\title{
Serials Services and Records Unit: Genealogy and General Information
}

\author{
Joan M. Quinn
}

In the beginning there was the Documents Checklist, which became the Continuations Checklist, which became the Check List, which begat the prodigal Current Check List, which became the Visible File and part of the Check List again, in plenty of time to see the Check List officially become the Central Serials Record, which now is incorporating the Current Serials Service, formerly the Periodical Reading Room and more formerly, the Gold Star Collection. Now, Serials Services and Records embraces them all.

Whatever you call it, the Check List is a main entry file containing all there is to know about serials holdings and acquisitions for the entire University Library system. If we keep it, discard it, or send it uncataloged, it's in the Check List. How we got it or how we get it (exchange, gift, standing order or separate order) is on the holding cards. There are order slips for new orders, and sometimes for awfully old ones. All this information is available if you understand how to use the Check List.

In the past, the Check List has contained current recordings for everything except quarterly and more frequently received periodicals. In the future, the only regularly received serials that will be recorded in the Check List are bound volumes; monographic titles that are analyzed or classed separately; and most multiple series. Everything else that is regularly received (including microfilm) will be in the Kardex (or Visible File), whichever we decide to call it.

\section{THE TEN COMMANDMENTS EXPANDED AND AMENDED FOR CHECK LIST RECORDERS}

I. Thou shalt Regard the Check List with Awe

Quinn, is Head of Serials Services and Records at the University of Michigan, Ann Arbor. and Reverence.

II. Thou shalt not transfer Thine Allegiance to any other Card Catalog.

III. Remember a Serial goes on Forever.* An Incomplete Separate is Finite, and not to be Regarded with Awe, but dispatched to Book Purchasing with all due Expediency.

IV. Thou shalt Honor Divisional Libraries before All Others, and Record for Them First. Divisional Librarians are not Silent as the Stacks, nor do they Sit and Patiently Wait for their "Advances in ...," and "Yearbooks on ... ," for which they Pay Exorbitant Sums.

V. Remember the Professors. They are slightly Below the Almighty. If They want Items Rushed, there's No Need to Ask Why. Rush them.

VI. Regard All Rare Book Room Items as Sacred. Thou must not put Call Numbers, Inscriptions or any other Markings, or even Bad Breathing, on a Rare Book Room Item. Without Exception.

VII. Render Thy Counters only to Monographs and Bound Volumes; A Gift to a Gift; an Exchange to an Exchange; and, above all, a Purchase to a Purchase.

VIII. Consider all Title Changes (even by a Jot or a Tittle) and Consult with a Serials Cataloger before Recording.

IX. Render unto Documents that which are Documents and unto $E$ \& $G$ that which can be Proven to be Without Price. E \& G does not Covet Purchased Items, nor Documents, nor will it Accept

*That is the Intention, but sometimes Aborted. 
Them. They will be Treated with Scorn and Disdain, and Returned with Aspersions and Calumny.

X. Thou shalt not Allow Monograph Catalogers to Gaze upon copy 2's and Anal'd Sets. Record Them and Send Them to Their Destinations with all due Haste. Monograph Catalogers have no Need or Desire to Know the number of Anal'd Copies Extant.**

XI. Thou Shalt Not Record added copies of Classed Separately Items; but thou shalt stamp the Search Slips so Monograph Catalogers will Think that you Have. There is No Other Way. You have no Call Numbers to Give Them, but you do have the Power to Decide where They go. Use it Discreetly. There must be an Order (Separate or Standing); or an Exchange, or a Gift that Somebody Somewhere Accepted. Otherwise no Classed Separately, or any Other Item, can go Anywhere, Except to Thine Supervisor, who has Wisdom, Judgement and Experience, which She will Impart to You, until you have Reached Maturity, and can be trusted to Uphold the Tradition without Undue Supervision.

XII. Regard all UFO's with Suspicion and Disfavor. Consult with Thine Supervisor about the Disposition of these Intruders. Their Number is Legion and Quite Beyond Reason.

XIII. Be Uneasy when Confronted with the Following Phrases (in any Language):
a. "Also published as ..."
b. "Simultaneously published as ..."
c. "Reprinted from ..."
d. "Originally published as ..."

These are Generally Outcasts and not to be Accepted Without Question.

XIV. Beware of the Prodigal Open Entry Anal. It has no Call Number of its Own, and Cannot Exist Without the Main Series. If, after a Diligent Search, You cannot Find the Main Series, Render the Book to a Serials Cataloger, Who will Supply It with a Call Number of Its Own, and a new Card for you to Record On. Open Entry Anal's are an Abomination and Should be Abolished.

XV. Record all Extracted Sets that Are no Longer in the Main Series with Joy and Thanksgiving. Extracted Sets have Their Own Call Numbers and can Always be Recorded, without Regard to the Absence of Any Other Series.

XVI. Consider the 99 Books in the Fold, and the One that was Lost in the Stacks, and Try Not to Lose One. That's the One They'll Remember. Forever.

\section{EPILOGUE}

All These Things have been Written in Other Forms, which No One Remembers. The Upholders of the Tradition are as Dust in the Stacks, and Will Soon be Forgotten. Everything Changes.

Amen becomes RLIN.

**Except in the Case of Lost Sheep from the Stacks. They are Replaced and Forgotten-As if they had Never Existed. Send Their Replacements to Analysis. 